\title{
Application of flood risk modelling in a web-based geospatial decision support tool for coastal adaptation to climate change
}

\author{
P. J. Knight ${ }^{1}$, T. Prime ${ }^{1,2}$, J. M. Brown ${ }^{2}$, K. Morrissey ${ }^{1}$, and A. J. Plater ${ }^{1}$ \\ ${ }^{1}$ Department of Geography and Planning, School of Environmental Sciences, University of Liverpool, Roxby Building, \\ Chatham Street, Liverpool L69 7ZT, UK \\ ${ }^{2}$ National Oceanography Centre Liverpool, Joseph Proudman Building, 6 Brownlow Street, Liverpool L3 5DA, UK \\ Correspondence to: P. J. Knight (philip.knight@liverpool.ac.uk)
}

Received: 16 January 2015 - Published in Nat. Hazards Earth Syst. Sci. Discuss.: 25 February 2015

Revised: 15 May 2015 - Accepted: 01 June 2015 - Published: 02 July 2015

\begin{abstract}
A pressing problem facing coastal decision makers is the conversion of "high-level" but plausible climate change assessments into an effective basis for climate change adaptation at the local scale. Here, we describe a web-based, geospatial decision support tool (DST) that provides an assessment of the potential flood risk for populated coastal lowlands arising from future sea-level rise, coastal storms, and high river flows. This DST has been developed to support operational and strategic decision making by enabling the user to explore the flood hazard from extreme events, changes in the extent of the flood-prone areas with sea-level rise, and thresholds of sea-level rise where current policy and resource options are no longer viable. The DST is built in an open-source GIS that uses freely available geospatial data. Flood risk assessments from a combination of LISFLOODFP and SWAB (Shallow Water And Boussinesq) models are embedded within the tool; the user interface enables interrogation of different combinations of coastal and river events under rising-sea-level scenarios. Users can readily vary the input parameters (sea level, storms, wave height and river flow) relative to the present-day topography and infrastructure to identify combinations where significant regime shifts or "tipping points" occur. Two case studies demonstrate the attributes of the DST with respect to the wider coastal community and the UK energy sector. Examples report on the assets at risk and illustrate the extent of flooding in relation to infrastructure access. This informs an economic assessment of potential losses due to climate change and thus provides local authorities and energy operators with essential information on the feasibility of investment for building resilience into vulnerable components of their area of responsibility.
\end{abstract}

\section{Introduction}

Society has entered a new era of climate change - one where the environmental consequences of warming are being observed and experienced directly, and in which the absence of timely, strategic intervention across the global community has taken us closer to more uncertain (non-linear, stochastic) and potentially more catastrophic change in the medium to long term (Lowe et al., 2009). With atmospheric $\mathrm{CO}_{2}$ concentrations having reached $400 \mathrm{ppm}$ (WMO, 2014), exceeding the "safe" threshold of $350 \mathrm{ppm}$, we have entered the period of "dangerous" climate change bearing witness to unprecedented loss of Arctic ice (Hodgkins, 2014) and accelerated rates of melting of the West Antarctic Ice Sheet (Sutterley et al., 2014). Set within this regime shift, sea-level rise during the 21 st Century may follow the trajectory of semi-empirical assessments (e.g. Jevrejeva et al., 2012, 2014) rather than the more conservative projections of the Intergovernmental Panel on Climate Change (IPCC) Fifth Assessment Report (Church et al., 2013). To avoid adaption planning being tied exclusively to institutional consensus on climate change projections, there is an urgent need for tools that provide decision makers with the opportunity to explore different potential futures in an open and informed environment (cf. Nicholls, 2002; Penning-Rowsell, 2015). Future sea-level rise coupled with changes in the magnitude and frequency of storm surges is a key focus for such a decision support tool (DST) because of the high (and growing) proportion of the world's population and associated infrastructure that occupies low-lying coastal regions (McGranahan et al., 2007; Nicholls et al., 2011; Hallegatte et al., 2013). 
A decision support system (DSS) is computer-based software that can assist policy makers and resource managers in their decision process (Iyalomhe et al., 2013). Within this definition there are sub-categories which are often used for describing environmental DSSs: spatial decision support systems (SDSSs) and environmental decision support systems (EDSSs) (Iyalomhe et al., 2013). SDSSs are often described as a combination of a DSS and a geographic information system (GIS). Shim et al. (2002) describe a SDSS for integrated river basin flood control using real-time data, model data, and a GUI (Graphical User Interface) interface flood control within a river basin. Furthermore, Zanuttigh et al. (2014a, b) describe and present case studies using an open-source SDSS, which was developed for the THESEUS project (www.theseusproject.eu); the tool allows users to perform an integrated coastal risk assessment. According to Matthies et al. (2007) a typical EDSS consists of a collection of environmental models, databases and management tools, which are integrated within a graphical user interface, that can utilise the spatial functionality provided by GIS. These DSS can provide evidence for decision makers in the sustainable management of natural resources and enable impact assessments of possible future adaptation and resilience. They can also assist local planners and emergency response personnel to better prepare and respond to sudden and/or extensive flooding events.

Following on from these types of systems are web-based geospatial tools (hereafter referred to as DSTs), which address the problems of earlier forms of DSSs in that they are easier to use and are more accessible to stakeholders and decision makers (Hearn et al., 2006; Hearn, 2009), while also providing detailed information. For example, the U.S. Geological Survey Flood Inundation Mapper (USGS, 2014) displays real-time river data and flood forecasts and includes mechanisms to incorporate results from flood mapping tools such as the HAZUS-MH (HAZUS Multi-Hazards) loss-estimation software (Hearn et al., 2013). This software provides data outputs for the economic and infrastructure loses due to flooding events. It is computationally intensive and is run offline, but it provides the output in a Web GIScompatible format. Likewise the Coastal Flood Atlas (USGS, 2014) displays modelled scenarios of flooding from storm surges along the east and Gulf coasts of the USA and incorporates estimates for the resulting economic and infrastructure losses. Furthermore, the National Oceanic and Atmospheric Administration (NOAA, 2014) has developed a GIS awareness tool to display the resulting inundation from storm surges along the US coastal states vulnerable to hurricanes. These worst-case flooding scenarios were constructed from the results of running a numerical model for hypothetical storms with different wind categories and high tide.

The web-based DST described here illustrates the potential flood risks for populated coastal lowlands arising from future sea-level rise, storms and high river flows. This DST supports operational (immediate) and strategic (long term, i.e. 10-100 years) decision making (cf. Ciavola et al., 2011) through the provision of an interface that enables the user to explore (i) areas and infrastructure presently at risk of flooding from extreme events, (ii) the extent to which this flood hazard changes with sea-level rise, and (iii) thresholds or tipping points where current policy options are no longer viable for locations at high risk of flooding. The DST is built in an open-source GIS that uses freely available geospatial data. Assessments of areas prone to flooding, through a combination of inundation and wave-overtopping models, are input to the DST where the user interface enables interrogation of different combinations of coastal and river events under risingsea-level scenarios. Within these options, established climate change projections (e.g. UKCP-09) may be highlighted to provide stakeholders with an "industry standard" assessment that feeds into strategic policy responses. Examples are also given where coastal stakeholders can readily vary the input parameters relative to the present-day topography and infrastructure to identify combinations where significant regime shifts may occur.

We present two case studies to demonstrate the attributes of the DST with respect to strategic and operational planning for a coastal community and the energy sector. In the strategic case study the examples report on the assets that are prone to flooding, illustrate the extent of flooding in relation to energy infrastructure access, and assess the likely depth, and hazard that extends well beyond planar assessments of respective elevation (i.e. land surface altitude vs. extreme level) (Bates et al., 2005). This can underpin an economic assessment of potential losses due to climate change and thus provides coastal users and energy operators with essential information on the feasibility of investment for building resilience into the present-day system to sustain long-term operations under future climate conditions. In the operational case study, examples show how storm surge forecasts and tidal predictions can support short-term decision making during events to limit impacts (e.g. life, well-being, economic costs) and to support effective deployment of resources.

\section{Web-based geospatial tools}

There are many technologies and methods available for building a web-based geospatial DST; however, this DST has been specifically developed to be easily upgraded and to make use of open-source components (with free licences). It has been designed to allow additional functionality to be incorporated and to allow inclusion of improved flood scenarios. The Appendix (glossary) section contains descriptions of some of the less-common technical terms and lists components used in developing this web-based tool.

The DST is built with two main website components (McBride, 2014): Bootstrap running within a PHP environment provides the HTML in a JavaScript and CSS style sheet, while Leaflet (Agafonkin, 2014), a JavaScript library, pro- 
vides the mapping framework. Slider bars have been developed using a jQuery JavaScript library so users can easily vary the input parameters. The back-end database used is POSTGRES with PostGIS added to provide the storage and allow querying of information about location and mapping. Additional data are imported as GeoJSON files from Web Feature Servers and other sources. The base maps are from OpenStreetMap (OSM, 2014) and Ordnance Survey (OS OpenData via Edina, 2014).

Users can control the display of spatial elements using a computer mouse on the top menu and the sidebar menu. The zoom-enabled base map and the superimposed flooding scenario can be selected with the sliders in the sidebar menu. This can be controlled using mouse panning movements and the clickable zoom facility. The sidebar menu contains the scenario control, flood analysis or operational results, information overlays, and base maps. With the sidebar menu, and depending on the chosen options, the user can vary sea-level rise, storm level, wave height, and river flow and view the resulting scenarios in a spatial flood map and tabulated results within the sidebar menu.

\section{Case studies}

Two UK case studies (see Fig. 1a) illustrate how stakeholders can use the current version of the DST: the first is a strategic coastal community case study located at Fleetwood, NW England (Fig. 1b), based on flooding from storm surges, waves and river flows; the second is an operational case study focused on the energy infrastructure at Oldbury-on-Severn, SW England (Fig. 1c), based on a storm surge event in January 2014.

\subsection{Strategic case study: Fleetwood, UK}

Fleetwood is a coastal town located in the Wyre District, Lancashire, NW England. It has a population of around 26000 people. The town is situated on a predominately sandy peninsula, around $3 \mathrm{~km}$ wide, bounded to the east by the River Wyre, to the north by Morecambe Bay, and to the west by the Irish Sea (see Fig. 1b). The land is extremely flat - the highest part is situated around The Mount (see Figs. $1 \mathrm{~b}$ and 2ad), where most of the original town developments took place. Much of the north and west of the town is just above the highest tidal level. There have been two major historic coastal flooding events: in 1927 and 1977. The 1927 event caused a breach in the sea wall resulting in loss of life as well as flooding (Times Digital Archive, 1927), while the 1977 event caused greater flooding to properties (Wyre Council, 2013). The highest astronomical tide (HAT) at Fleetwood is $5.56 \mathrm{~m}$ ordnance datum (OD), mean high water spring tide (MHWS) is $4.21 \mathrm{~m} \mathrm{OD}$, and the maximum tidal range is $10.17 \mathrm{~m}$. Tidal predictions were computed using the POLTIPS- 3 tidal prediction software provided by the NOC Marine Data Prod- ucts Team. At Heysham, $14 \mathrm{~km}$ to the north of Fleetwood, the highest storm surge recorded was $1.6 \mathrm{~m}$ in 1988 (NTSLF, 2014).

\subsection{Operational case study: Oldbury-on-Severn, UK}

Oldbury-on-Severn is a small rural village in South Gloucestershire, SW England. It is situated alongside Oldbury Pill, a small river which flows into the Severn Estuary (see Fig. 1c). The surrounding area is mainly used for agriculture, and there is also a decommissioned Magnox nuclear power station (see Figs. 1c and 3a-b) $2 \mathrm{~km}$ to the north-west. Although the power station ceased operating in 2012, there are decommissioning and maintenance processes taking place which will be ongoing for many decades. In addition there are plans for a new nuclear power station to be sited just to the north of the current location.

The surrounding low-lying land, typically between 5.0 to $7.5 \mathrm{~m} \mathrm{OD}$, is drained by small channels known locally as rhines. In this area they drain towards a pumping station at Oldbury Naite (see Figs. 1c and 3a-b) where the combined flows are discharged into Oldbury Pill. This low-lying land is protected by gently sloping earth defences which were designed to protect against overtopping by the $1: 50 \mathrm{yr}$ extreme water level (EWL). There is enhanced protection at the former nuclear power station, which has sheet piles (some parts have concrete sloping features extending down towards the estuary from the base of the sheet pile structures) with a minimum crest height of $9.97 \mathrm{~m} \mathrm{OD}$. To the north and south of the site, the earth sea defences rise to $9.5 \mathrm{~m} \mathrm{OD}$ with localised minima of $9.0 \mathrm{~m} \mathrm{OD}$ : for example, at the flood gate where the Oldbury Pill flows into the Severn Estuary (see Figs. 1c and $3 \mathrm{a}-\mathrm{b}$ ). HAT at Oldbury-on-Severn (Narlwood Rocks) is $8.54 \mathrm{~m} \mathrm{OD}$, MWHS is $7.03 \mathrm{~m} \mathrm{OD}$, and the maximum tidal range is $13.14 \mathrm{~m}$. At Avonmouth, $16 \mathrm{~km}$ to the south-west of Oldbury-on-Severn, the highest storm surge recorded was $1.95 \mathrm{~m}$ in 1997 (NTSLF, 2014).

\section{Flood modelling}

Flood scenarios were generated using the LISFLOOD-FP flood inundation model, originally developed by Bates and De Roo (2000). Additional LISFLOOD-FP inputs for waves were computed using the Shallow Water And Boussinesq (SWAB) model developed by McCabe (2011). Environment Agency $2 \mathrm{~m}$ resolution airborne laser altimetry (LiDAR) data were interpolated onto 5 and $10 \mathrm{~m}$ grids (Fleetwood and Oldbury-on-Severn, respectively) to reduce model computation time. Sea defences were adjusted by replacing the interpolated value with the highest $2 \mathrm{~m}$ data point within the 5 or $10 \mathrm{~m}$ grid box to reincorporate them after feature smoothing. Furthermore, where detailed sea defence data were available (e.g. parts of the Fleetwood model domain), these were used in preference. 

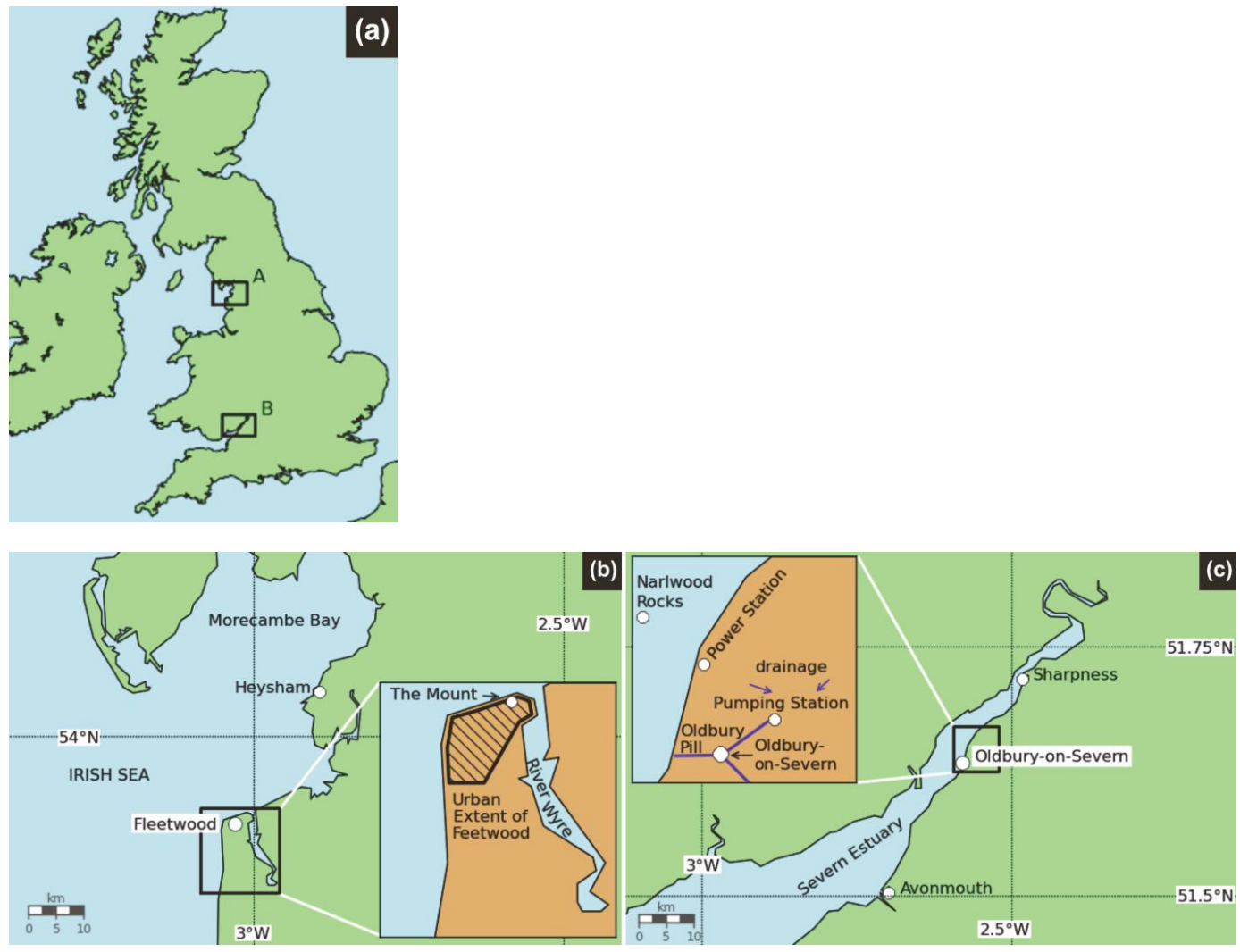

Figure 1. (a) UK map showing the locations of the two case studies: (A) strategic case study centred upon Fleetwood, (B) operational case study centred upon Oldbury-on-Severn. (b) Map showing location of strategic case study centred upon Fleetwood; urban extent of Fleetwood and The Mount. (c) Map showing location of operational case study centred upon Oldbury-on-Severn; Oldbury Pill, pumping station and nuclear power station.

The case study based on Fleetwood (Fig. 1b) displays flood scenarios and the resulting economic costs taken from Prime et al. (2015). The scenarios consider the economic impact of flood events from sea-level rise, storm tides, wave overtopping and high river flow. Economic cost estimates were produced for each grid box and based upon land characteristics; arable land (arable and horticulture, improved grassland, rough grassland, and neutral grassland), residential housing, roads, and industrial land-use (industrial buildings). These costs were computed by combining the maximum flood depths for each grid box with saltwater damage curves (data source: Prime et al., 2015, following PenningRowsell et al., 2013). A full explanation of the cost analysis and the implications for coastal planners can be found in Prime et al. (2015). Each scenario within the Fleetwood case study has been computed using time-varying boundary conditions along the coastline, which are constant in space and represent storm (tide plus surge) elevations. Furthermore, the tidally varying boundary conditions consist first of EWLs (still-water levels only; i.e. surface wave fluctuations are not included). Additional boundary forcing is incorporated at the coastal defences to account for the influence of extreme wave heights (EWHs) and also include extreme river levels (ERLs) at the upper estuary boundary. Further scenarios were generated for sea-level rise in $10 \mathrm{~cm}$ increments. For clarity in the web-based interface, EWLs are labelled as storm level, EWHs are labelled as wave height, and ERLs are labelled as river flow. Although the user selects a return period for the EWH or ERL, the information input into the inundation model is the consequent time-varying wave overtopping rate and river discharge that would occur in response to that forcing locally.

The case study data for Oldbury-on-Severn (Fig. 1c) have also been computed using the same LISFLOOD-FP approach described in Prime et al. (2015). It excludes the economic cost analysis and has no wave and river inputs; this location is largely protected from waves due to its location within the Severn Estuary (Magnox, EU Stress Test Report for Oldbury, 2011), and it has a relatively small flood risk contribution from Severn river flow when compared with the contribution from the extreme water level. Extreme precipitation events within the catchment behind the sea defences are an additional source of flooding; however, this was not included as part of this case study.

As with Fleetwood, each scenario for the Oldbury-onSevern case study has been computed using time-varying 
(a)

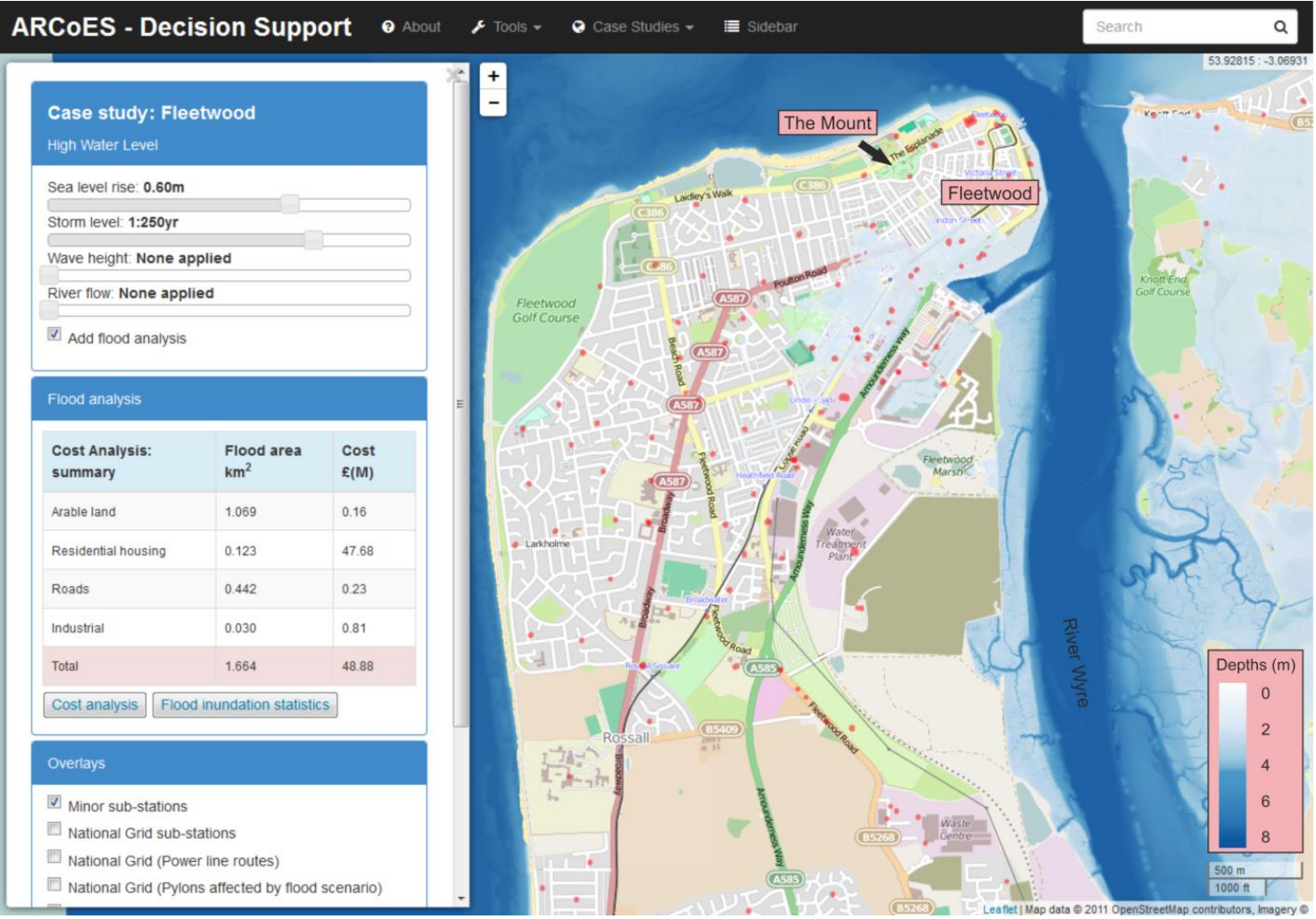

(b)
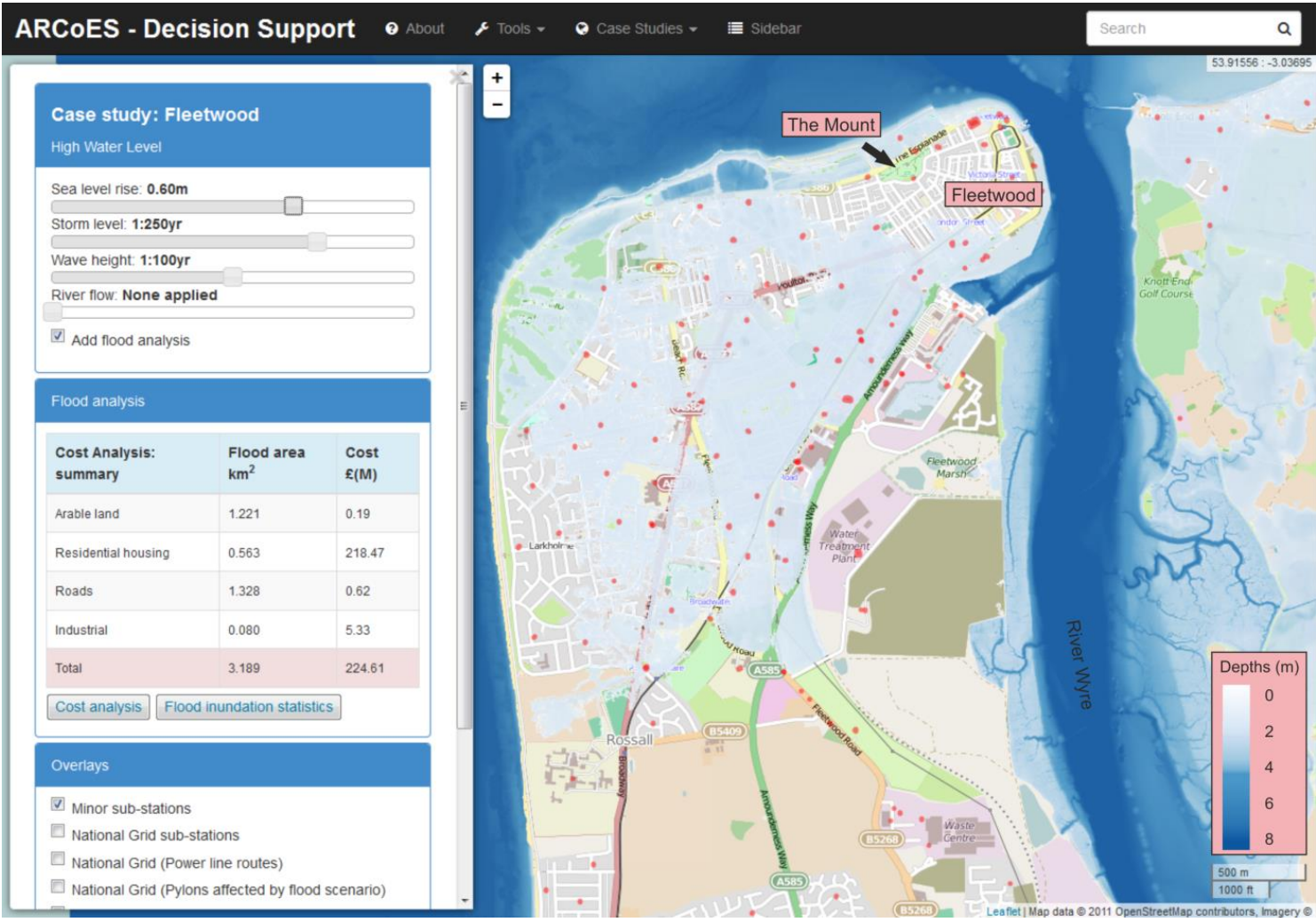

Figure 2. (a) DST screen shot of the scenario with a $0.6 \mathrm{~m}$ sea-level rise and a $1: 250$ year storm level (extreme water level). Note: labels with dark-pink backgrounds have been added to screen shot. (b) DST screen shot of the scenario with a $0.6 \mathrm{~m}$ sea-level rise, a 1:250 year storm level (extreme water level), and a 1:100 year wave height (extreme wave height). Note: labels with dark-pink backgrounds have been added to screen shot. 
(c)

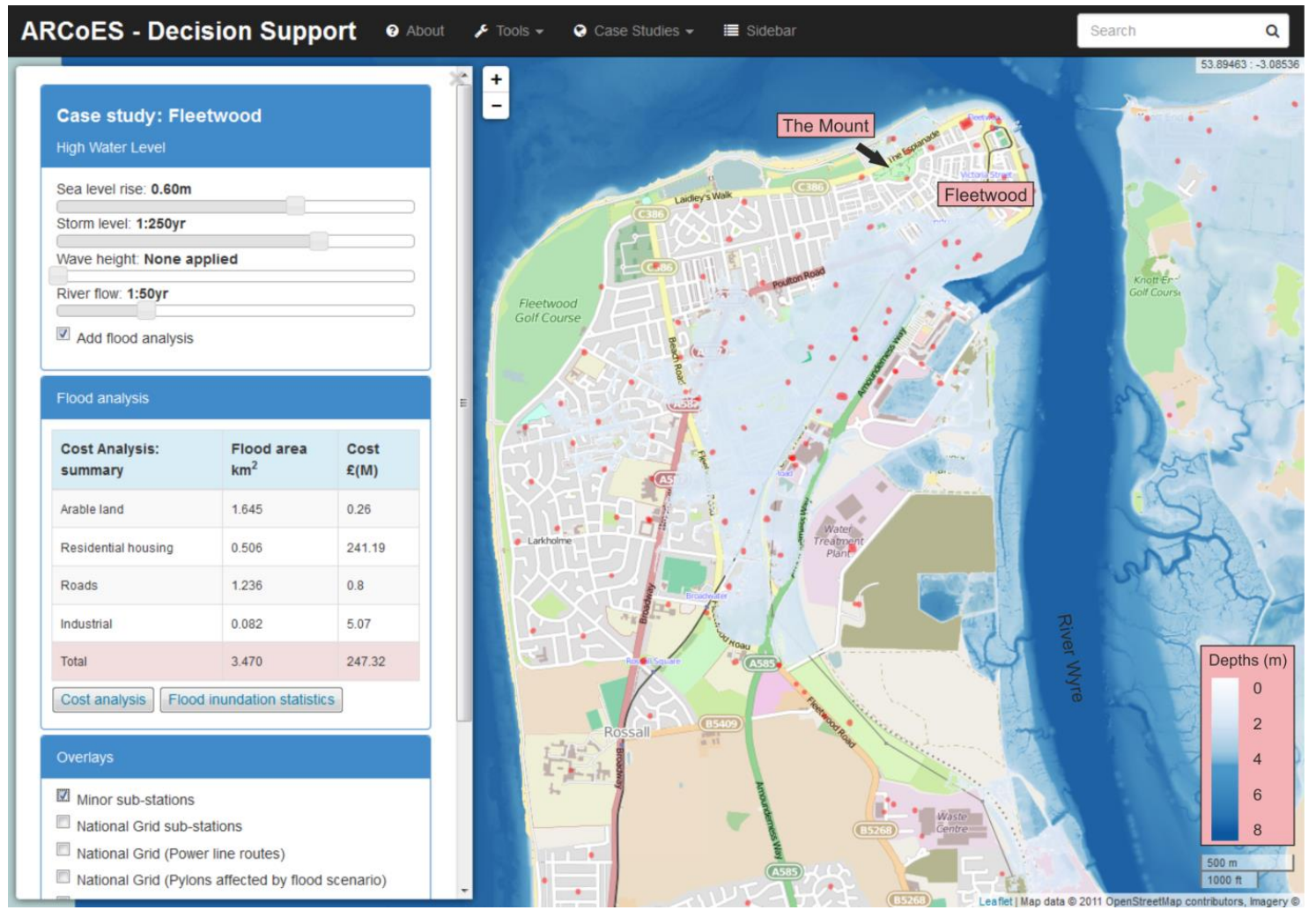

(d)
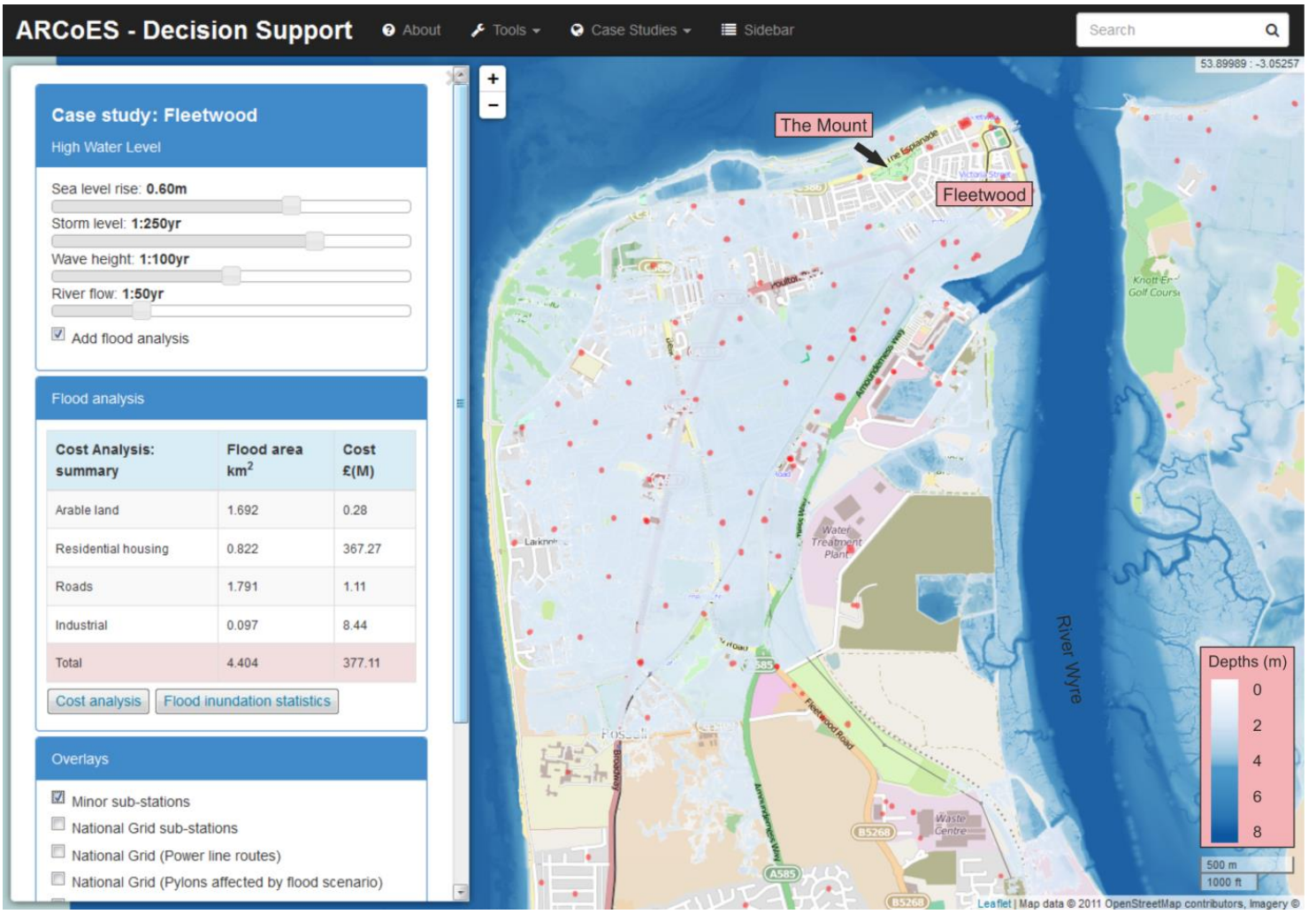

Figure 2. (c) DST screen shot of the scenario with a $0.6 \mathrm{~m}$ sea-level rise, a 1:250 year storm level (extreme water level), and $1: 50$-year river flow (extreme river level). Note: labels with dark-pink backgrounds have been added to screen shot. (d) DST screen shot of the scenario with a $0.6 \mathrm{~m}$ sea-level rise, a $1: 250$ year storm level (extreme water level), a $1: 100$ year wave height (extreme wave height), and $1: 50$-year river flow (extreme river level). Note: labels with dark-pink backgrounds have been added to screen shot. 
(a)

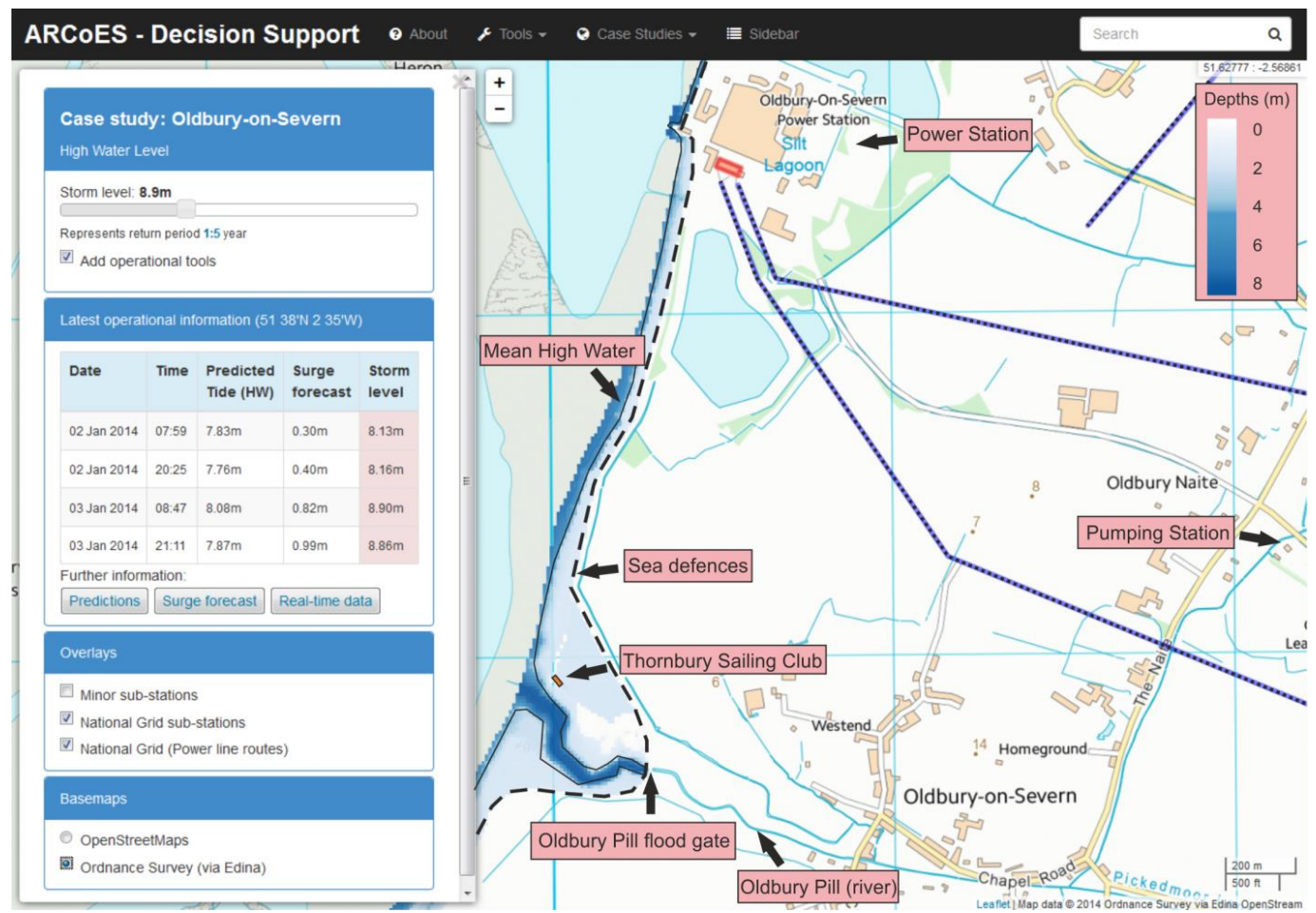

(b)

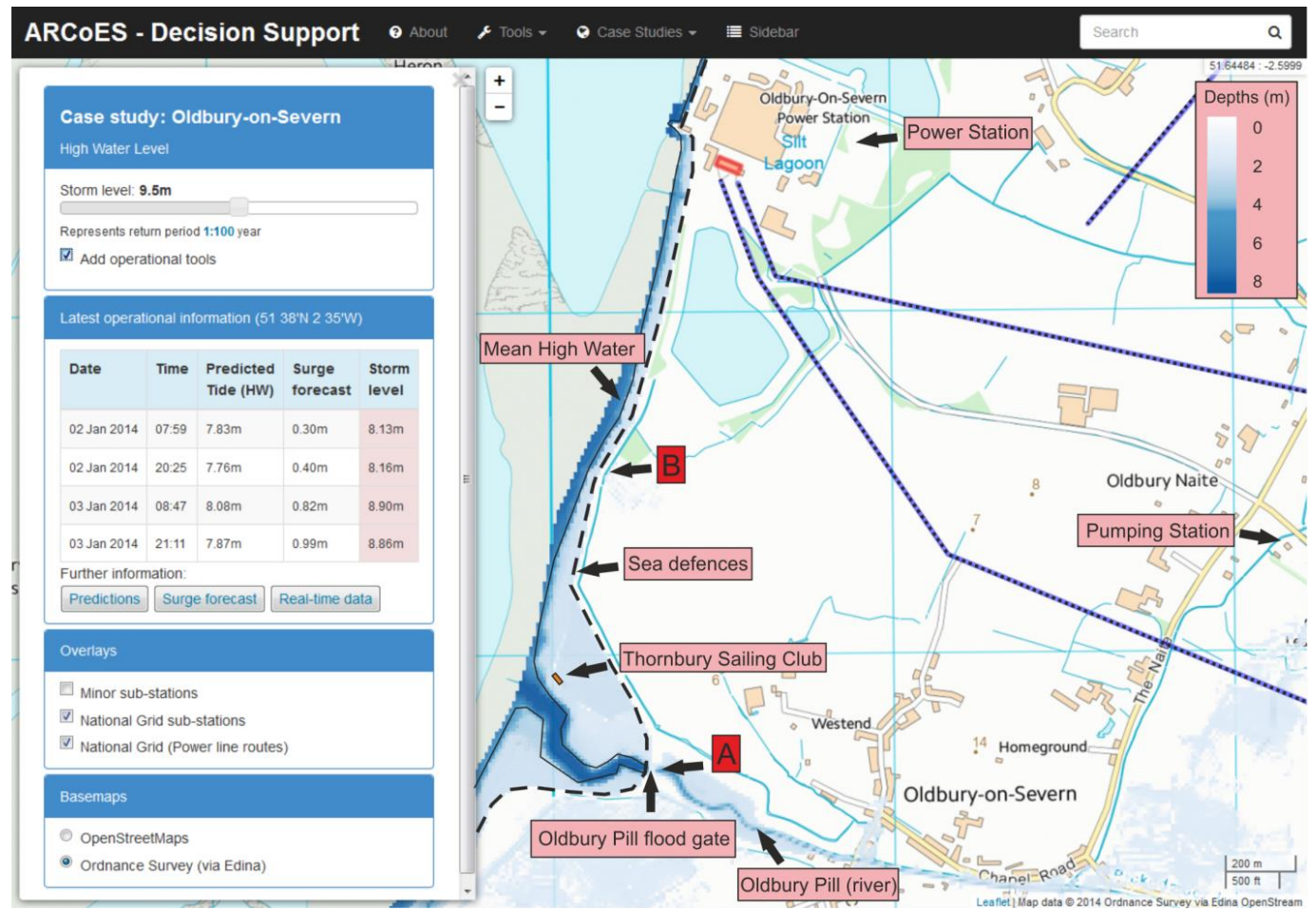

Figure 3. (a) DST screen shot of the scenario with a $8.9 \mathrm{~m}$ storm level (extreme water level) (surge forecast of the 3 January 2014 storm used as a guide). Sea defences (black dashed line), sub-stations (red boxes), and power routes (black dashed lines with blue background) are overlain. No flooding occurs behind the sea defences. Flooding extent: around the Thornbury Sailing Club site. Note: labels with dark-pink backgrounds have been added to screen shot. (b) DST screen shot of the "what-if scenario" with a $9.5 \mathrm{~m}$ storm level (extreme water level). Sea defences (black dashed line), sub-stations (red boxes), and power routes (black dashed lines with blue background) are overlain. Note: labels with dark-pink and red backgrounds have been added to screen shot. Labels A and B represent locations of over-washing. Flooding extent: main flooding via Oldbury Pill with minor flooding behind sea defences at (B). (c) DST screen shot of the sidebar components (see Fig. $3 \mathrm{~b}$ for full screen shot including map): slider bar, operational tools, overlays, and base maps. 
boundary conditions along the coastline, which are constant in space and represent storm time (tide plus surge) elevations. Again, each tidal curve was adjusted to include a localised storm surge shape, as described within the Practical Guidance Design Sea Levels (EA, 2011a) and Design Sea Levels (EA, 2011b) manuals. Since a curve was not available for Oldbury-on-Severn, the storm surge shape for Avonmouth was used to represent all locations along the modelled coastline. This resulted in a set of scenarios from a $1: 1$ year EWL to a $1: 10000$ year EWL event. As an additional element of the Oldbury-on-Severn case study, a tipping-point analysis was undertaken whereby a visualisation of future sea-level rise in $10 \mathrm{~cm}$ increments enables the user to explore critical extreme level elevations at which significant changes in flood risk, or at least the area prone to flooding, take place. The purpose here is to provide an understanding of where present defence strategy, e.g. "hold the line", will no longer be viable under present operational resourcing.

Every scenario for each case study produced a data set of maximum flood extent in the standard ESRI ASCII raster format. These were visually checked using the desktop Quantum GIS $(Q G I S)$. They were then transformed using the $G D A L$ library scripts into smaller tiles following the OSGeo Tile Map Service (TMS) specification. This allowed zooming functionality to be incorporated within the map server set-up.

\subsection{Results for Fleetwood, UK}

Figure $2 \mathrm{a}-\mathrm{d}$ show a selection of images from the web-based DST illustrating the strategic application of the tool. The "minor sub-stations" overlay box has been ticked (minor substations are denoted by red markers) to show the density of electricity infrastructure across Fleetwood and the surrounding area. The summary cost analysis results of the corresponding scenario can also be displayed, with links to further analysis and downloads. Figure 2 a shows the slider bars set to sea-level rise $(0.6 \mathrm{~m})$, storm level $(1: 250 \mathrm{yr})$, wave height (none applied) and river flow (none applied). The summary flood analysis within the menu display includes a cost analysis breakdown according to land-use type of the chosen flood scenario: arable land GBP 0.16 M (area flooded: $1.069 \mathrm{~km}^{2}$ ), residential housing GBP $47.68 \mathrm{M}$ (area flooded: $0.123 \mathrm{~km}^{2}$ ), roads GBP $0.23 \mathrm{M}$ (area flooded: $0.442 \mathrm{~km}^{2}$ ), and industrial GBP 0.81 M (area flooded: $0.03 \mathrm{~km}^{2}$ ).

Figure $2 \mathrm{~b}$ shows the sliders bars set to sea-level rise $(0.6 \mathrm{~m})$, storm level $(1: 250 \mathrm{yr})$, wave height $(1: 100 \mathrm{yr})$, and river flow (none applied). A substantial increase in the area prone to flooding can be observed (shaded in light blue) relative to Fig. 2a on both sides of the River Wyre, with a substantial area of urban land-use flooded within Fleetwood. Figure $2 \mathrm{c}$ shows the sliders bars set to sea-level rise $(0.6 \mathrm{~m})$, storm level ( $1: 250 \mathrm{yr}$ ), wave height (none applied), and river flow $(1: 50 \mathrm{yr})$. In this case, flooding due to wave overtopping is reduced and the urban area prone to flooding is re- duced relative to Fig. $2 \mathrm{~b}$ and located away from the marine shoreline. Lowland areas either side of the Wyre channel are flood-prone due to the high river levels. A combination of extreme water level, wave overtopping and high river flow is given in Fig. 2d, in which the sliders bars are set to sea-level rise $(0.6 \mathrm{~m})$, storm level $(1: 250 \mathrm{yr})$, wave height $(1: 100 \mathrm{yr})$, and river flow $(1: 50 \mathrm{yr})$. Although the general location and extent of flooding is similar to that shown in Fig. 2b, local detail shows a marked difference in the flood-prone urban area to the east and south-east of the Fleetwood.

\subsection{Results for Oldbury-on-Severn, UK}

This case study shows how the DST can be used operationally to support the deployment of resources immediately before and during an event. For example in January 2014 a large tide coincided with a medium-sized storm surge. This event was one in a series experienced in the UK, leading to the stormiest winter on record (Matthews et al., 2014). On 2 January 2014 the storm surge 2-day forecast (NTSLF, 2014) issued for individual high waters varied between 0.30 and $0.99 \mathrm{~m}$, while the predicted astronomical tide ranged between 7.83 and $8.08 \mathrm{~m}$ OD. The storm surge forecast at Oldbury-on-Severn was $0.82 \mathrm{~m}$, which when combined with the predicted astronomical tidal high water at $08: 47$ on 3 January gave a total storm level of $8.9 \mathrm{~m} \mathrm{OD.}$

Figure $3 \mathrm{a}-\mathrm{c}$ show screen shots from the web-based display for extreme water levels of $8.9 \mathrm{~m}$ and $9.5 \mathrm{~m} \mathrm{OD}$, respectively, and display the corresponding flood mapping scenarios. In this case the menu system displays the latest operational storm surge forecasts. The base map used for these scenarios was from the Ordnance Survey (OS, 2014). Local power infrastructure information such as major sub-stations (denoted by red boxes) and electricity pylon routes (denoted by black dashed lines with blue background) can be overlaid by selecting (ticking) the appropriate boxes. Using this information, the stakeholder can view pre-computed flood maps based on the total extreme levels by moving the relevant slider bars and hence explore "what-if scenarios" in support of their own evaluations of risk or, indeed, how actions and deployments might need to evolve during the course of an event. In these examples the site of the former nuclear power station at Oldbury-on-Severn is unaffected since it is relatively well protected and built on a platform above $9.9 \mathrm{~m} \mathrm{OD}$; however, it is possible to display the more extreme scenarios to determine the flood hazard in relation to access roads (e.g. for timely site evacuation or the effective intervention of emergency measure and services).

Subsequent analysis of the tide gauge data at the Oldburyon-Severn nuclear power station suggested that the extreme water level was closer to $8.5 \mathrm{~m} \mathrm{OD}$. This did not over-wash the Environment Agency (EA) sea defences as is also evident in the scenario with the extreme water level set to $8.9 \mathrm{~m} \mathrm{OD}$. However, the sailing club at Thornbury (see Fig. 3a) did experience flooding (Thornbury Sailing Club, personal com- 
(a)

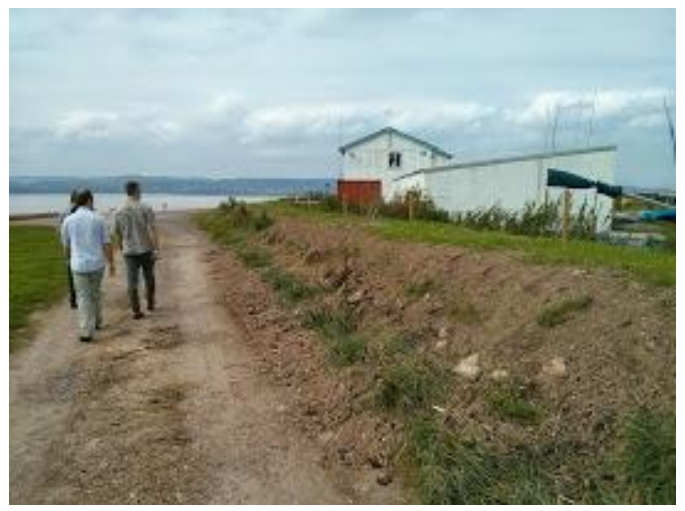

(b)

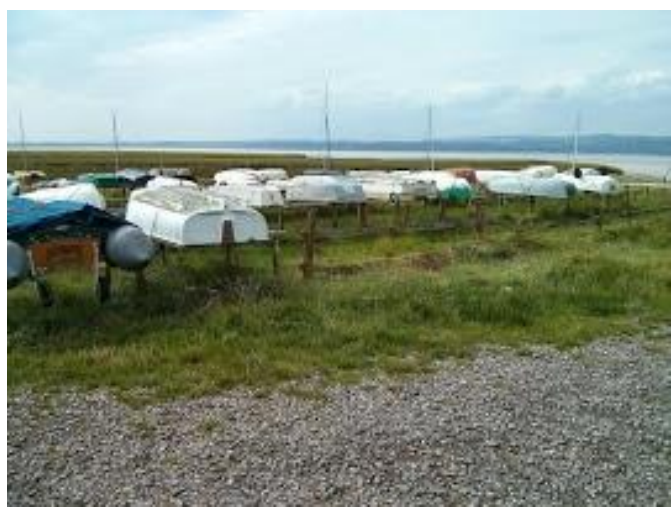

(c)

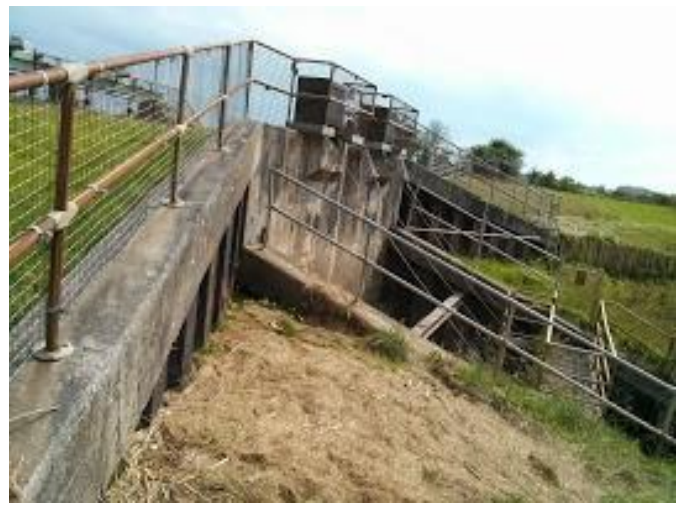

Figure 4. (a) Thornbury Sailing Club: localised club sea defences can be seen to the right of the track (Note: this area is situated between high-water and EA sea defences). (b) Thornbury Sailing Club: adaption to flooding events (boats stored on stilts) (Note: this area is situated between high-water and EA sea defences). (c) Oldbury Pill flood gate: one of the lower points indicated by LiDAR. Debris can be seen in the foreground, indicating the likely water level of the January 2014 event.

munication and the club's newsletter, 2014). The sailing club is located on a triangle of land at the entrance to the Oldbury Pill between the high-water mark and the EA sea defences. Consequently it is more vulnerable to flooding than sites behind the main sea defences. Figure 3a shows a scenario in which flooding in this triangle occurs for an extreme water level of $8.9 \mathrm{~m} \mathrm{OD}$, representing a storm level return period of $1: 5$ years. The sailing club has started to adapt to these types of flooding events by building localised defences and installing boat and dinghy storage on stilts (Fig. $4 \mathrm{a}$ and b).

Figure $4 \mathrm{c}$ shows the flood gate at the Oldbury Pill, near to the sailing club (see Fig. 3a). Debris can be seen in the foreground, indicating the water level of a recent event. Figure $3 b$ shows results from the scenario with the extreme water level set to $9.5 \mathrm{~m} \mathrm{OD}$. In this case there are two over-wash events: one at the Oldbury Pill flood gate and another smaller one just to the north, as indicated in Fig. 3b by A and B, respectively. This scenario represents a return period storm level of $1: 100$ years.

A tipping-point visualisation is presented in Fig. 5 as a sequence of maps illustrating the extent of potential flooding arising from a 1:5-year EWL combined with sea-level rise of between 0.0 and $1.0 \mathrm{~m}$ in $10 \mathrm{~cm}$ increments. It is apparent that a significant shift in the area at risk from EWL flooding occurs at $0.5 \mathrm{~m}$ sea-level rise, with considerable increases in areal extent thereafter. In this case, it would appear that the current shoreline management plan strategy and resourcing would not require significant re-evaluation until this threshold is reached, enabling stakeholders to then explore further when this tipping point might be reached or how likely it would be reached following a given decision-making time horizon. While this is perhaps more strategic in its focus, the analysis also shows how operations would need to deal with quite different extents of flood hazard.

\section{Discussion}

It has become more and more evident that our understanding of potential climate change impacts requires regular revision and reflection. This is only a logical consequence of improving understanding of the fundamental science and system interdependencies but also how the climateocean-cryosphere system has changed through time, irrespective of actions to limit emissions. Although the IPCC Fifth Assessment Report (Church et al., 2013) provides an update on the scientific consensus on future sea-level change, other plausible low-probability sea-level projections provide a different set of sea-level futures (Vermeer and Rahmstorf, 2009; Jevrejeva et al., 2012, 2014). At the same time, local government, regulatory authorities, and coastal stakeholders have become almost constrained by an "industry standard" set of climate projections, in the UK provided by the UK Climate Impacts Programme (UKCP-09) (see http://ukclimateprojections.metoffice.gov. uk/22568). Coupled with these projections of sea-level rise and storms, the coastal stakeholder community is presented with an array of approaches for probabilistic risk assessment linked to different emissions scenarios and climate system responses (Nicholls, 2004; Dawson et al., 2005; Hall et al., 2006; Purvis et al., 2008; Nicholls et al., 2011; Lewis et al., 2011). Consequently, it is essential to fully engage with in- 

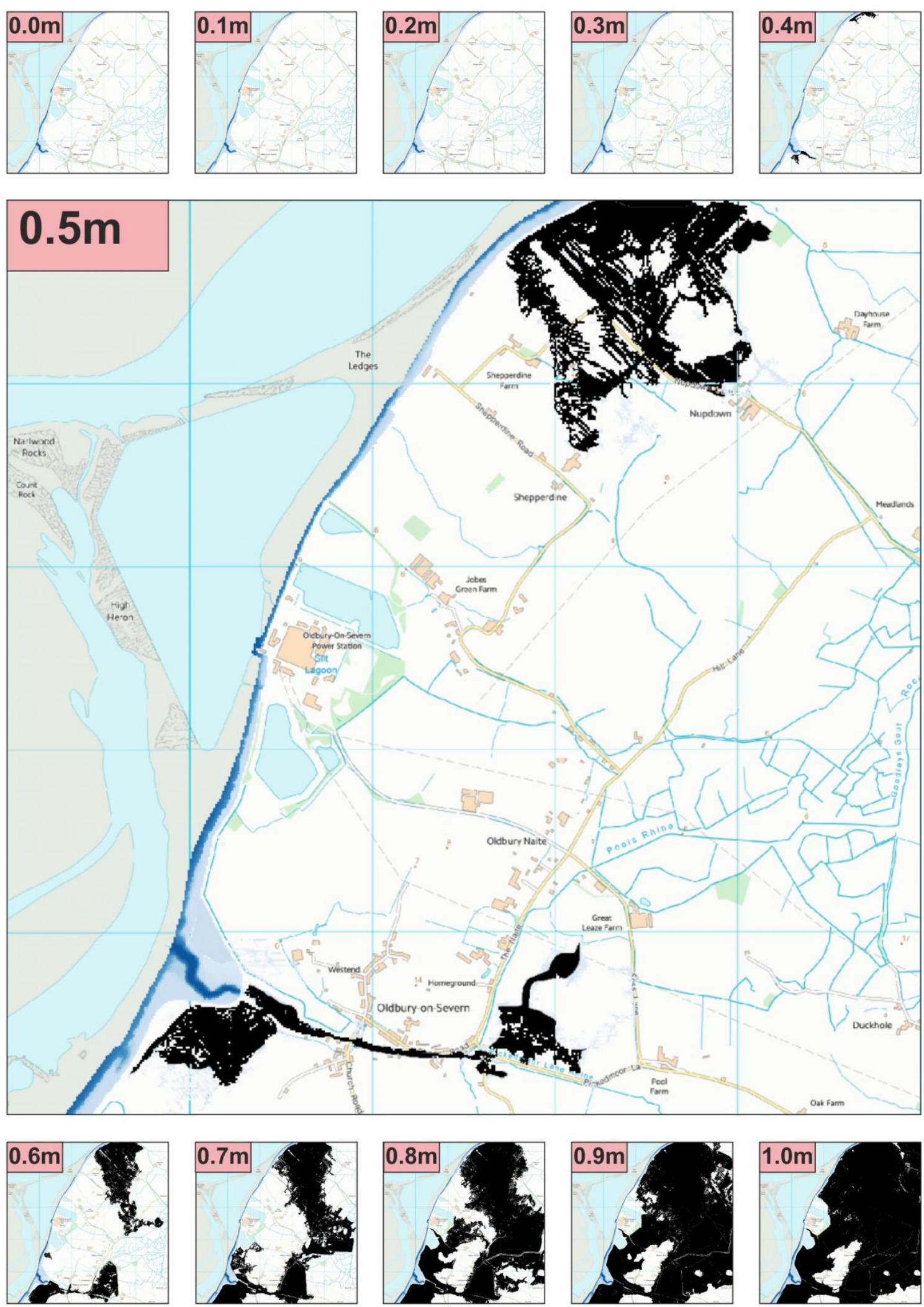

Figure 5. Maps of potential flooding due to a 1-in-5-year extreme water level under $0.0-1.0 \mathrm{~m}$ sea-level rise in $10 \mathrm{~cm}$ increments (black areas indicate the flood water extent behind the sea defences). A "tipping point" in the area prone to flooding is seen at $0.50 \mathrm{~m}$ of sea-level rise, with substantial increases in areal extent thereafter. 
formation needs of coastal decision makers and stakeholders in designing accessible and easy-to-use geospatial tools that enable a range of climate change scenarios to be explored in an open and informed way (de Moel et al., 2009; Dawson et al., 2011; Wadey et al., 2013).

Furthermore, these tools must acknowledge that decisions are made within overarching environmental, economic, and societal contexts (McGranahan et al., 2007; Van Koningsveld et al., 2008; Dawson et al., 2011), but where institutional priorities are not necessarily constructed in a socially inclusive framework. Hence, the DST is designed for use by a wider community of stakeholders rather than addressing any specific sectorial or institutional agenda. This DST provides scenarios based around coastal flooding caused by storm surges, waves, and river levels, and combined with predicted sealevel rise scenarios. In addition to being applied in a strategic sense, examining changes in the nature and extent of floodprone areas, the DST can be used to support flood management operations when extreme water levels (storm, waves, and rivers) are forecast to be close to the sea defence height limits.

The DST described here has taken a slightly different approach to the NOAA (2104) DST, by using open-source mapping tools and displaying flood scenarios computed using extreme water level statistics as boundary conditions for the LISFLOOD-FP inundation model. Furthermore, it provides the options to include additional contributions from flooding due to wave overtopping and river flows. Also, by focusing on small areas, like Fleetwood and Oldbury-on-Severn, it is feasible to compute many more scenarios (e.g. smaller increments of sea-level rise over a broader range of elevations) with finer spatial resolutions (e.g. $10 \mathrm{~m}$ grid). This improves the flooding estimates by taking into account smaller features within the digital elevation model.

\subsection{Strategic application}

In addition to providing considerable detail on areas prone to flooding from future storms and sea-level rise, the Fleetwood DST clearly demonstrates the differential susceptibility of the urban area and energy infrastructure to wave overtopping and river flow, both in isolation and combination. By including SWAB model outputs within the modelling, a range of flooding scenarios based upon wave overtopping have been included. Previous historical events have shown that large amounts of water have transferred over the sea defences by wave action without an over-wash or breach taking place (Wyre Council, 2013). In terms of the key strategic benefits of the DST, these range from simple exploration of the relative significance of different drivers of flood hazard (and their combination) to being a user-friendly tool that does not require specialist knowledge or access to expensive software. The Fleetwood case study demonstrates how the DST can be used to support strategic decisions over the medium to long term in relation to flood defence options; this is illustrated further by the Oldbury-on-Severn tipping-point analysis. In essence, the DST allows for the user to explore where flooding is likely under different combinations of sea-level rise, storm magnitude, wave height, and river discharge, as well as how these areas are likely to change in location and extent in the future with projected sea-level rise. Consequently, the DST provides a mechanism for visualising how future flood hazard compares with the present, and thus how and where shoreline management planning may need to change according to the scale of the problem. In terms of mapping, the DST helps users to identify where key strategic interventions could be located to afford an effective level of reduced risk for a sizeable asset base over a good vertical range of sea-level rise.

Like the Coastal Flood Atlas (USGS, 2014) the DST shown here for Fleetwood can incorporate estimates for the economic and infrastructure losses, and also include scenarios based upon sea-level rise for the next 100 years. A more detailed discussion of the Fleetwood case study in relation to the cost implications of coastal flooding can be found in Prime et al. (2015); however, the results shown here give the decision maker the opportunity to explore the likely financial consequences of various scenarios. For example, based upon comparing the wave and river scenarios separately, a decision maker for Fleetwood may conclude that it would be more cost-effective to upgrade the defences along one side of the river, allow flooding across rural land to the east of the town, and keep the western sea defences at the same height.

\subsection{Operational application}

The Oldbury-on-Severn case study largely describes an operational application of the DST. It demonstrates how stakeholders can view a storm surge forecast and assess the likely outcome in terms of localised flooding (areas affected, timing, likely depth and duration of floodwaters). The tremendous advantage of this DST is that it presents both specialist and non-specialist users with a means for exploring the local impacts and detail of a predicted regional-scale phenomenon, as well as how these impacts are likely to evolve through the event. Even something as simple as detail on where and when flooding is likely to occur may significantly reduce losses and financial/well-being implications, such as when to move vehicles and where to move them to; advance warning on properties likely to be evacuated without requiring emergency intervention; and how long infrastructure or routes are likely to be inaccessible due to flood depth and duration. The local sailing club at Thornbury have now started to adapt to flooding events by constructing localised defences around the club house (Fig. 4a); the DST would indicate when and where these would require deployment if used on a temporary basis. The DST also allows the decision maker to apply what-if scenarios to assess resilience for both operational and strategic purposes. For example, users have the ability to examine flood scenarios based on building-up the sea walls; such a 
proposal has been made by the Environment Agency to increase the height of the existing sea defences by $1.5 \mathrm{~m}$ along the coast from Oldbury-on-Severn to Sharpness by 2030. The slider facility in the DST is specifically designed to enable assessment of the relative significance of different drivers of coastal flooding and the consequences of their combined operation, i.e. non-linearity in the areas prone to flooding.

\subsection{Longevity of the DST}

This DST has been designed to incorporate new requests from coastal decision makers - e.g. community data sets on other infrastructure, assets, or evacuation routes - and for the flood scenarios to be updated as modelling advances and updated assessments of flood risk (climate-related projections, extreme level magnitude and frequency, probability, economic cost, etc.) become available. Also, since it is based upon open-source software, it can be easily hosted and developed by other research groups without incurring licence costs.

This DST is a component part of a project called Adaption and Resilience of Coastal Energy Supply (ARCoES), which includes a data management plan to safeguard research outputs. Therefore, all documentation, data, source code, and model output will be archived within OpenARCC (http://www.arcc-network.org.uk/openarcc): a data management initiative. In addition, these will also be made available within a web resource alongside the web-based DST, allowing the user to fully construct the DST from its individual parts.

Before making this open-source DST publicly available, a series of trials for selected user groups will be conducted. It is intended to update the DST following user feedback to ensure that the DST addresses key questions and concerns from across the coastal stakeholder community and that it enables users to fully understand the capabilities and limitations of using the flooding scenarios. An ongoing iteration following feedback from the UK energy sector is to develop the DST to investigate flooding around the bases of electricity pylons. Most pylons would be able to cope with minor flood events; however more frequent flooding events and deeper flows, resulting in larger velocity speeds, have the potential to affect the foundations. Saturated sediments underneath tower bases could cause pylons to lean beyond their designed tolerances. Furthermore, faster flows could start to erode sediment surrounding the pylons and again cause leaning. This would require extracting flow rates as well as water depths from the LISFLOOD-FP model outputs and using additional geological data. This illustrates a route to further funding which, by engaging with stakeholders throughout the development phase of the DST, can lead to the future longevity of the tool.

\section{Conclusions}

An open-source, web-based geospatial decision-support tool has been developed that allows the energy sector and the wider coastal stakeholder community to explore the likely flood impacts of future climate change scenarios. Two case studies describe how the DST can be used for strategic and/or operational requirements. The Fleetwood case study demonstrates the areas prone to flooding from sea-level rise, storm surges, high waves and high river flows, and combinations thereof, as well as how these are likely to change in the future. This can be coupled with a land-use and depthdamage methodology to highlight the financial consequences of climate change within a populous coastal community. The Oldbury-on-Severn case studies highlights the vulnerability of important electricity supply infrastructure and the surrounding low-lying rural area to coastal flooding, with an emphasis on short-term decision making immediately before and during a storm event. Here the emphasis is to minimise economic losses and limit threats to human health and well-being. The DST also offers the capability to undertake a tipping-point analysis of coastal resources, aiming to identify significant shifts in areas prone to flooding when the present management policy option would be untenable.

The work illustrates the importance of an open-source DST within which a range of users can explore the potential impacts of future climate change scenarios and drivers of coastal flooding according to their own interests and priorities without any institutional or licensing constraint. The key element here is to develop the DST as an experimental environment that can be updated according to information needs of coastal stakeholders and the availability of data. In the absence of a structured probability framework, the emphasis is on the user to take responsibility for their own assessment of likelihood from the range of available sea-level projections.

Further work would include re-computing the flooding scenarios for Oldbury-on-Severn using the recent localised sea defences which have been installed by the Thornbury sailing club. The current scenarios were run using LiDAR data collected before installation. In addition, an option for increasing sea defence height within the DST and viewing the resulting scenarios would provide some insight into proposed infrastructure developments. 


\section{Appendix A}

Table A1. Glossary.

\begin{tabular}{|c|c|}
\hline Bootstrap: & $\begin{array}{l}\text { a sleek, intuitive, and powerful mobile first front-end framework for faster and easier } \\
\text { web development }\end{array}$ \\
\hline Leaflet: & a modern open-source JavaScript library for mobile-friendly interactive maps \\
\hline jQuery: & $\begin{array}{l}\text { a fast, small, and feature-rich JavaScript library which includes, e.g., slider bar } \\
\text { development }\end{array}$ \\
\hline Quantum GIS: & a free and open-source desktop geographic information system similar to ArcGIS \\
\hline GDAL: & $\begin{array}{l}\text { geospatial Data Abstraction Library is a library for reading and writing raster } \\
\text { geospatial data formats }\end{array}$ \\
\hline PostgreSQL: & an object-relational database management system \\
\hline PostGIS: & $\begin{array}{l}\text { provides spatial objects for the PostgreSQL database, allowing storage and query of } \\
\text { information about location and mapping }\end{array}$ \\
\hline OpenStreetMap: & an openly licensed map of the world \\
\hline PHP & is a server-side scripting language \\
\hline GeoJSON & is a format for encoding a variety of geographic data structures \\
\hline
\end{tabular}


Acknowledgements. The authors thank their colleagues at the National Oceanography Centre (NOC) and their Marine Data Products Team for providing tidal data, storm surge modelling forecasts, and tidal prediction software; Magnox for providing additional sea defence data and tidal data; Environment Agency for providing lidar data and tidal data; Gloucester Harbour Trustees for providing tidal data; and National Grid \& Electricity Northwest Limited for providing electricity infrastructure data. This work was supported by grants EP/1035390/1 (ARCoES) and an EPSRC Impact Acceleration Account administered through the University of Liverpool.

Edited by: P. Ciavola

Reviewed by: three anonymous referees

\section{References}

Agafonkin, V.: Leaflet: open source Javascript library for mobile friendly interactive maps, available at: http://www.leafletjs.com, last access: 10 November 2014.

Bates, P. D. and De Roo, A. P. J.: A simple raster-based model for flood inundation simulation, J. Hydrol., 236, 54-77, 2000.

Bates, P. D., Dawson, R. J., Hall, J. W., Horritt, M. S., Nicholls, R. J., and Wicks, J.: Simplified two-dimensional numerical modelling of coastal flooding and example applications, Coast. Eng., 52, 793-810, 2005.

Ciavola, P., Ferreira, O., Haerens, P., Van Koningsveld, M., and Armaroli, C.: Storm impacts along European coastlines. Part 2: lessons learned from the MICORE project, Environm. Sci. Pol., 14, 924-933, 2011.

Church, J. A., Clark, P. U., Cazenave, A., Gregory, J. M., Jevrejeva, S., Levermann, A., Merrifield, M. A., Milne, G. A., Nerem, R. S., Nunn, P. D., Payne, A. J., Pfeffer, W. T., Stammer, D., and Unnikrishnan, A. S.: Sea Level Change. In: Climate Change 2013: The Physical Science Basis. Contribution of Working Group I to the Fifth Assessment Report of the Intergovernmental Panel on Climate Change, edited by: Stocker, T. F., Qin, D., Plattner, G.K., Tignor, M., Allen, S. K., Boschung, J., Nauels, A., Xia, Y., Bex, V., and Midgley, P. M., Cambridge University Press, Cambridge, United Kingdom and New York, NY, USA, 2013.

Dawson, R. J., Hall, J. W., Bates, P. D., and Nicholls, R. J.: Quantified analysis of the probability of flooding in the Thames estuary under imaginable worse-case sea level rise scenarios, Water Resour. Develo., 21, 577-591, 2005.

Dawson, R. J., Ball, T., Werritty, A., Hall, J. W., and Roche, N.: Assessing the effectiveness of non-structural flood management measures in the Thames Estuary under conditions of socioeconomic and environmental change, Global Environ. Change, 21, 628-646, 2011.

Environment Agency (EA): Coastal flood boundary conditions for UK mainland and islands, Project: SC060064/TR4: Practical guidance design sea levels, ISBN 978-1-84911-214-7, February 2011a.

Environment Agency (EA): Coastal flood boundary conditions for UK mainland and islands, Project: SC060064/TR2: Design sea levels, ISBN 978-1-84911-212-3, February 2011b.

Hall, J. W., Sayers, P. B., Walkden, M. J. A., and Panzeri, M.: Impacts of climate change on coastal flood risk in England and
Wales: 2030-2100, Philos. Trans. Roy. Soc. A, 364, 1027-1049, 2006.

Hallegatte, S., Green, C., Nicholls, R. J., and Corfee-Merlot, J.: Future flood losses in major coastal cities, Nat. Clim. Change 3, 802-806, doi:10.1038/nclimate1979, 2013.

Hearn Jr., P. P.: Web-based geospatial tools to address hazard mitigation, natural resource management, and other societal issues: U.S. Geological Survey Fact Sheet 2009-3022, available at: http: //pubs.usgs.gov/fs/2009/3022, 1-4, 2009.

Hearn, P. P., Wente, S. P., Donato, D. I., and Aguinaldo, J. J.: EMMMA: A Web-based system for environmental mercury mapping, modeling, and analysis: U.S. Geological Survey Open-File Report 2006-1086, available at: http://pubs.usgs.gov/of/2006/ 1086/, 1-17, 2006.

Hearn, P. P., Longenecker III, H. E., Aguinaldo, J. J., and Rahav, A. N.: Delivering integrated HAZUS-MH flood loss analyses and flood inundation maps over the Web, J. Emergency Manage., 11, 293-302, 2013.

Hodgkins, R.: The twenty-first-century Arctic environment: accelerating change in the atmospheric, oceanic and terrestrial spheres, Geograph. J., 180, 429-436, 2014.

Iyalomhe, F., Rizzi, J., Torresan, S., Gallina, V., Critto, A., and Marcomini, A.: Inventory of GIS-Based Decision Support Systems Addressing Climate Change Impacts on Coastal Waters and Related Inland Watersheds, Climate Change - Realities, Impacts Over Ice Cap, Sea Level and Risks, edited by: Bharat, R. S., ISBN: 978-953-51-0934-1, InTech, doi:10.5772/51999, available at: http://www.intechopen.com/books/climate-changerealities-impacts-over-ice-cap-sea-level-and-risks/, 2013.

Jevrejeva, S., Moore, J. C., and Grinsted, A.: Sea level projections to $\mathrm{AD} 2500$ with a new generation of climate change scenarios, Global Planet. Change, 80-81, 14-20, 2012.

Jevrejeva, S., Grinsted, A., and Moore, J. C.: Upper limit for sea level projections by 2100 , Environ. Res. Lett., 9, 1-9, doi:10.1088/1748-9326/9/10/104008, 2014.

Lewis, M., Horsburgh, K., Bates, P., and Smith, R.: Quantifying the uncertainty of future coastal flood risk estimates for the U.K., J. Coastal Res., 27, 870-881, 2011.

Lowe, J. A., Howard, T. P., Pardaens, A., Tinker, J., Holt, J., Wakelin, S.,Milne, G., Leake, J., Wolf, J., Horsburgh, K., Reeder, T., Jenkins, G., Ridley, J.,Dye, S., and Bradley, S.: UK Climate Projections science report: Marine and coastal projections. Met Office Hadley Centre, Exeter, UK, 2009.

Magnox: EU Stress Test Report for Oldbury, available at: http://www.magnoxsites.co.uk/wp-content/uploads/2014/03/ EU-Stress-Test-Report-for-Oldbury.pdf (last access: 24 June 2015), 1-80, 2011.

Matthews, T., Murphy, C., Wilby, R. L., and Harrigan, S.: Stormiest winter on record for Ireland and UK, Nat. Clim. Change, 4, 738740, 2014.

Matthies, M., Giupponi, C., and Ostendorf, B.: Environmental decision support systems: Current issues, methods and tools, Environ. Modell. Softw., 22, 123-127, 2007.

McBride, B.: Building an open source responsive web mapping template, 8th Annual Central Florida GIS 2014 workshop, available at: www.cfgisworkshop.com, last access: 10 November 2014.

McBride, B.: Github repositories, available at: https://github.com/ bmcbride, last access: 10 November 2014. 
McCabe, M.: Modelling Nearshore Waves, Runup and Overtopping, University of Manchester, Thesis, 2011.

McGranahan, G., Balk, D., and Anderson, B.: The rising tide: assessing the risks of climate change and human settlements in low elevation coastal zones, Environ. Urban., 19, 17-37, 2007.

de Moel, H., van Alphen, J., and Aerts, J. C. J. H.: Flood maps in Europe - methods, availability and use, Nat. Hazards Earth Syst. Sci., 9, 289-301, doi:10.5194/nhess-9-289-2009, 2009.

National Oceanic and Atmospheric Administration: National Hurricane Center, Storm Surge Inundation, available at: http://noaa.maps.arcgis.com/apps/StorytellingTextLegend/ index.html?appid=b1a20ab5eec149058bafc059635a82ee, last access: 15 December 2014.

NTSLF: National Tidal \& Sea Level Facility, Storm Surge Climatology, available at: http://www.ntslf.org/storm-surges/ storm-surge-climatology/, last access: 14 November 2014.

Nicholls, R. J.: Analysis of global impacts of sea-level rise: a case study of flooding, Phys. Chem. Earth, 27, 1455-1466, 2002.

Nicholls, R. J.: Coastal flooding and wetland loss in the 21 st Century: changes under the SRES climate and socio-economic scenarios, Global Environ. Change, 14, 69-86, 2004.

Nicholls, R. J., Marinova, N., Lowe, J. A., Brown, S., Vellinga, P., De Gusmão, D., Hinkel, J., and Tol, R. S. J.: Sea-level rise and its possible impacts given a "beyond $4{ }^{\circ} \mathrm{C}$ world" in the twenty-first century, Philos. Trans. Roy. Soc. A, 369, 161-181, 2011.

Ordnance Survey (OS) via Edina: OpenData [WMS web map service], Coverage: UK, Ordnance Survey, GB. Using: EDINA Digimap Ordnance Survey Service, available at: http://edina.ac. uk/digimap, last access: November 2014.

OpenStreetMap (OSM): OSM files (UK), available at: http://planet. openstreetmap.org/, last access: 18 November 2014.

Penning-Rowsell, E. C.: A realistic assessment of fluvial and coastal flood risk in England and Wales, Trans. Institute of British Geogr., 40, 44-61, 2015.

Penning-Rowsell, E., Priest, S., Parker, D., and Morris, J.: Flood and Coastal Erosion Risk Management, 2013th Edn., Routledge, doi:10.3390/jpm3040288, PMID:25566432, 2013.

Prime, T., Brown, J. M., and Plater, A. J.: Physical and Economic Impacts of Sea-Level Rise and Low Probability Flood Events on Coastal Communities, PLOS ONE, 10, e0117030, doi:10.1371/journal.pone.0117030, 2015.

Purvis, M. J., Bates, P. D., and Hayes, C. M.: A probabilistic methodology to estimate future coastal flood risk due to sea level rise, Coastal Eng., 55, 1062-1073, doi:10.1016/j.coastaleng.2008.04.008, 2008.

Shim, K., Fontane, D., and Labadie, J.: Spatial Decision Support System for Integrated River Basin Flood Control, J. Water Resour. Plann. Manage., 128, 190-201, 2002.
Sutterley, T. C., Velicogna, I., Rignot, E., Mouginot, J., Flament, T., van den Broeke, M. R., van Wessem, J. M., and Reijmer, C. H.: Mass loss of the Amundsen Sea Embayment of West Antarctica from four independent techniques, Geophys. Res. Lett., 41, doi:10.1002/2014GL061940, 2014

Thornbury Sailing Club, available at: http://www.thornburysc.org. uk/, last access: 18 November 2014.

The Times Digital Archive: Flood Damage, Times, London, England, 31 October, 14. Archive. Web, 1927.

U.S. Geological Survey (USGS): Flood Inundation Mapping Science, http://water.usgs.gov/osw/flood_induation/: Flood Inundation Mapper, http://wim.usgs.gov/FIMI: HAZUS-MH flood loss analysis tools, http://water.usgs.gov/osw/flood_inundation/ toolbox/hazus.html, last access: 12 December 2014.

U.S. Geological Survey (USGS): Web-based GIS Decision Support Tools, available at: http://www.usgs.gov/climate_landuse/ lcs/projects/web_gis.asp, last access: 12 December 2014.

Van Koningsveld, M., Mulder, J. P. M., Stive, M. J. F., VanDerValk, L., and VanDerWeck, A. W.: Living with sea-level rise and climate change: a case study of the Netherlands, J. Coast. Res., 24, 367-379, 2008.

Vermeer, M. and Rahmstorf, S.: Global sea level linked to global temperature, Proc. Natl. Acad. Sci., 106, 21527-21532, doi:10.1073/pnas.0907765106, 2009.

Wadey, M. P., Nicholls, R. J., and Haigh, I.: Understanding a coastal flood event: the 10 March 2008 storm surge event in the Solent, UK, Nat. Hazards, 67, 829-854, doi:10.1007/s11069-013-06105,2013

WMO, World Meteorological Organization: $\mathrm{CO}_{2}$ concentrations top 400 parts per million throughout northern hemisphere. Press Release No. 991, 26 May, available at: http://www.wmo.int/ pages/mediacentre/press_releases/pr_991_en.html, 2014.

Wyre Council: - Rossall Project Appraisal, Rossall Coastal Defence Improvement Scheme, Authority scheme reference RCDS/FPCP/KP, Environment Agency MTP No. NWC013F/000A/001A, March, V1, available at: http://www.wyre.gov.uk/downloads/ (last access: 9 December 2014), 2013

Zanuttigh, B., Simcic, D., Bagli, S., Bozzeda, F., Pietrantoni, L., Zagonari, F., Hoggart, S., and Nicholls, R. J.: THESEUS decision support system for coastal risk management, Coast. Eng. 87, 218-239, doi:10.1016/j.coastaleng.2013.11.013, 2014a.

Zanuttigh, B., Nicholls, R., Vanderlinden, J. P., Burcharth, H. F., and Thompson, R. C. (Eds.): Coastal Risk Management in a Changing Climate, Butterworth-Heinemann, ISBN978-0-12-397310-8, 2014b. 